\title{
Information System for Registering the Result of Scientific Institution Employees' Intellectual Activity
}

\author{
Svetlana Vlasova ${ }^{1[0000-0003-1533-5850]}$, Nikolay Kalenov 2[0000-0003-5269-0988] \\ 1-2 Joint Supercomputer Center of RAS - branch of Federal State Institution «Scientific Re- \\ search Institute for System Analysis of RAS, Leninskiy pr., 32a, 119334, Moscow, Russia \\ 1 vlas.svetlana2013@yandex.ru, 2nekalenov@mail.ru
}

\begin{abstract}
The article describes an object-oriented WEB-system designed for storing and providing various reference and statistical data on the scientific works of employees of an institution (group of institutions), developed by specialists of the Joint Supercomputer center of Russian Academy of Sciences (JSCC RAS). The system contains information about publications of employees and reports made by them at scientific conferences, symposiums, and seminars. The system is focused on working with objects belonged to classes connected between each other, such as "author", "organization", "publication", "report", "event". The metadata profile of objects of each class includes attributes that are necessary to get detailed information about both an individual object of this class and a group of objects associated with the specified attribute values of objects of other classes. For example, you can get a list of articles by employees of a given organization published articles in a given journal for a given period of time. A distinctive feature of the system is the introduced concept of "equivalent" objects. Such objects are "persons" corresponding to the same author with different spellings of the last name in the bibliographic descriptions of publications; organizations with different versions of names; articles which are published without changes in different languages. This article describes in detail the features of the system, its user interface, and provides examples of performing specific queries.
\end{abstract}

Keywords: databases, research results accounting, WEB-based system, network technologies, publication activity analysis, software.

\section{Introduction}

The approaches developed in Russia to assessing the effectiveness of research carried out by scientific organizations are largely based on assessments of the publication activity of their employees. Recently, new criteria for assessing the effectiveness of scientific activity are based not only on a quantitative, but also on a qualitative assessment of publication activity, in particular, on the characteristics of the journal in which this or that article is published.

\footnotetext{
Copyright (C) 2020 for this paper by its authors.

Use permitted under Creative Commons License Attribution 4.0 International (CC BY 4.0).
} 
The growth in the number of scientific publications, the increasing requirements for the different kinds of reporting associated with the results of the intellectual activities of scientists, necessitate the creation of information and reference systems that allow solving problems in this area.

In the Russian Academy of Sciences, the tasks of accounting for the publications of employees were traditionally solved by libraries serving a particular institution. For decades, many libraries kept filing cabinets of employees' works, and with the development of computer technology, they switched to maintaining the corresponding databases. Although databases of publications of employees of institutes play an important role in the problems of scientometrics (which is convincingly shown in [1]), there is no unified approach to the formation of such databases. Some libraries or institutes maintain a database of employees' publications in EXCEL, some - based on their own software, many are limited to lists of publications presented in the form of text files [2-6].

In modern conditions, when for each organization the issues of accounting for publications (and, more broadly, the results of intellectual activity, including reports at scientific conferences, received patents, copyright certificates) are of great importance, it seems appropriate to develop a standard system that solves the general problem of forming and maintaining a database of results intellectual activity of one or another team of scientists. Such system was developed at the JSCC RAS, taking into account the experience of previous developments by the authors [7, 8].

\section{System structure}

In The system operates with 5 related classes of objects - "person", "publication", "organization", "report", "event". The publication class includes three related subclasses - publication at the analytical level (article in a journal, collection); publication at the monographic level (book, brochure, magazine issue, etc.); publication at the summary level (journal, collection). For each class, its own metadata profile (a list of mandatory and optional attributes) of the objects included in it has been developed, and the types of relationships between objects within the class and outside it are defined.

A fundamental feature of this system that distinguishes it from other similar systems is the introduction of links between objects of the "equivalent records" type. The objects connected in this way are perceived by the system as identical. The need to enter equivalent persons is due to the fact that the spelling of the surname and first name of the same author in different bibliographic descriptions may differ. For example, in the English-language publications of the person "Сотников А.Н." you can find the following spellings of this author: "Sotnikov A.N.", "Sotnikov A.", "A. Sotnikov", "A.N. Sotnikov", "Alexander Sotnikov".

The equivalence of publications arises when an article in the original language and its fully translated versions into another language are reflected in the database. The relationship of equivalence for organizations is established when an organization that does not change in essence changes its name (for example, the Library for Natural 
Sciences of the USSR Academy of Sciences and the Library for Natural Sciences of the Russian Academy of Sciences). Due to the presence of equivalence links, when processing a request containing one of the values of a particular attribute, the system will show a result related to all equivalent values of this attribute.

As an example, we present the metadata profiles of objects of the class "person", "event" and the subclass "publication at the analytical level"; (r) after the name of the attribute means that the attribute is required, (o) - optional.

A person ${ }^{1}$ :

$\checkmark \quad$ Surname and initials of the author (r);

$\checkmark$ Additional information (o);

$\checkmark$ Links to organizations (r);

$\checkmark$ Links to equivalent personas (o).

Event:

$\checkmark \quad$ Event name (r);

$\checkmark$ The type of event (conference, seminar, etc.) is selected from a custom list of values $(\mathrm{r})$;

$\checkmark \quad$ Venue of the event (country, city) (r);

$\checkmark$ Event dates (presented in normalized form (start date - end date):

yyyy.mm.dd - yyyy.mm.dd (r);

$\checkmark$ Event website address (o);

$\checkmark$ Site address with event materials (o);

$\checkmark$ Additional information (o).

Analytical level publication:

$\checkmark \quad$ Publication title (r);

$\checkmark \quad$ The type of publication (article from a journal, collection, abstracts, etc.) is selected from a custom list of values (r);

$\checkmark \quad$ Year of publication (r);

$\checkmark$ Monographic level object reference (r);

$\checkmark$ Pages (r);

$\checkmark \quad$ Address of the full text of the publication (o);

$\checkmark$ Identifiers in external databases (in particular, DOI) (o);

$\checkmark$ Citation in WoS (o);

$\checkmark$ Citation in Scopus (o);

$\checkmark$ Citation in RSCI (o);

$\checkmark \quad$ Links to persons who are the authors (r);

$\checkmark$ Links to equivalent publications (o);

$\checkmark$ Additional information (o).

\footnotetext{
${ }^{1}$ In order to avoid conflict with the legislation on the protection of personal data, when describing a person, the minimum information that identifies an employee of this organization is used.
} 
All operations related to entering and editing data in the system can be performed only by authorized users, therefore, along with the above, the system uses objects of the "Operator" type containing information about authorized users and their rights when working with the system.

Access rights are divided into two categories: system administrator and operator rights. The administrator has the right to enter and edit data about operators and edit all data of the system infobase. The operator has the ability to enter and edit the publications of the employees of the organization he represents.

The system consists of two modules: administrative (http://dirsmsc.ru/bd/adm.aspx) and user (http://dirsmsc.ru/bd

\section{Administrative module of the system}

The following processes are carried out in the administrative module:

$>$ input and editing of data on operators working with the system;

$>$ entering new records of publications, reports, events, persons, organizations;

$>$ editing the metadata of all objects;

$>$ search and viewing of objects registered in the system;

$>$ creating groups of equivalent records.

Let's consider the process of entering publications and reports into the system. Entering data for a new publication begins with entering its authors in the order presented in the publication. For each author, the presence of his metadata in the system is checked, if they are absent, the process of registering a new person is launched. The author's data (surname and initials, additional information) are entered into the system and their connection with an organization that either already exists in the system or is registered as new is formed.

After completing the entry of authors, the system opens a form for entering publication metadata: title, type (article, monograph), source, year of publication, volume, number, pages, full text address, identifiers in external databases (Fig. 1). When entering the title of the publication, the system shows the already registered publications (by the coincidence of the authors and the first words of the title). To link it to the published source (the publication of the summary level where the article is published), it must be found by fragments of the title, and if absent, registered in the system (to enter the title and additional information). After all the necessary metadata has been entered, the publication will be registered in the system. 


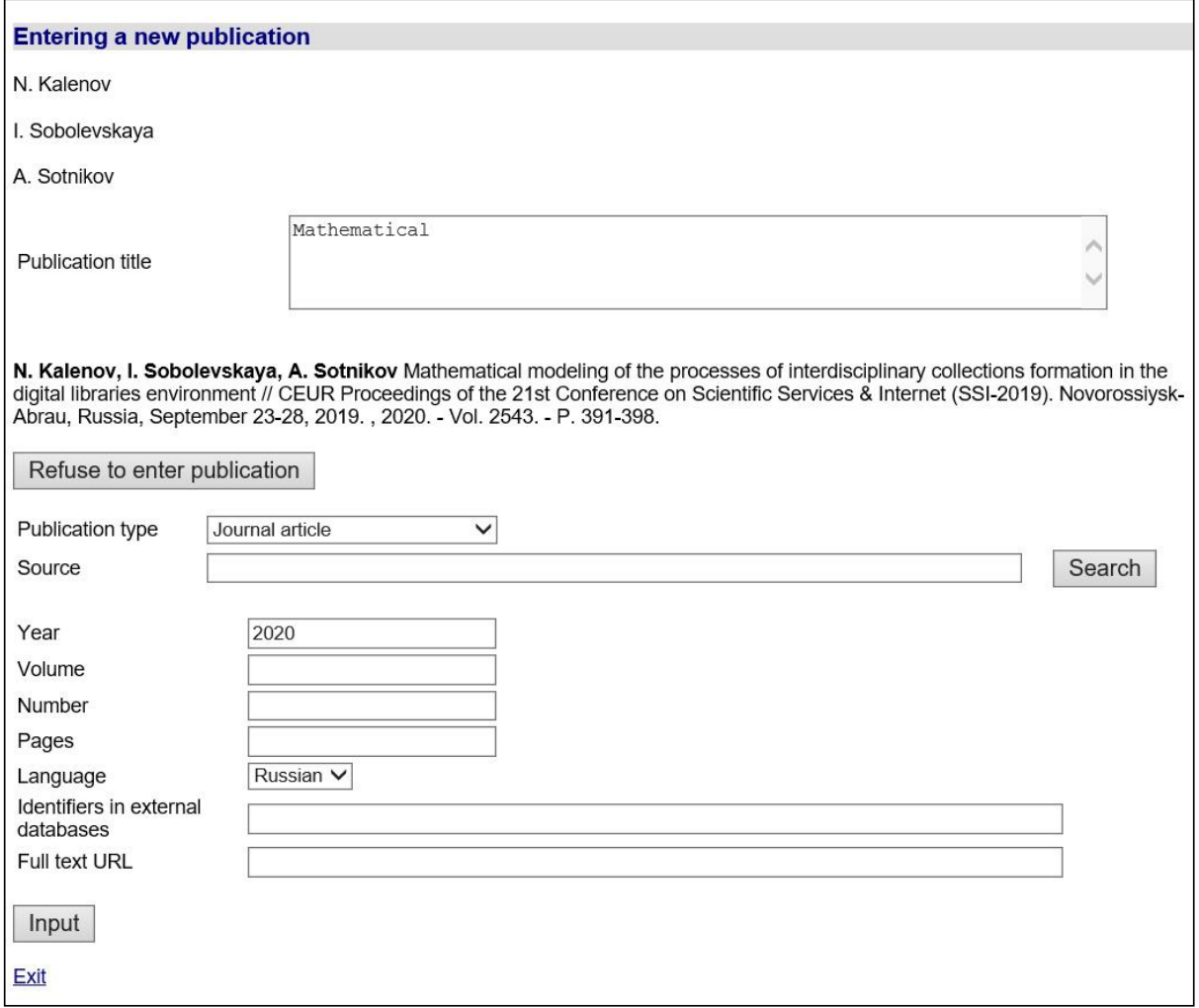

Fig. 1. Registration of publication

Registration of a new report, as well as registration a new publication, begins with the input of authors. Then the system provides a form for entering the metadata of the report: the title of the report, the type of the report (plenary, section, poster, invited), additional information. The must be linked to the corresponding event. The fragments of the event name are used to determine its presence in the system. If it is absent, a form is provided to enter it, including: type of event (conference, seminar, symposium, meeting); location (city and country); dates of the event (start and end); link to the event website; links to published materials (Fig. 2). 


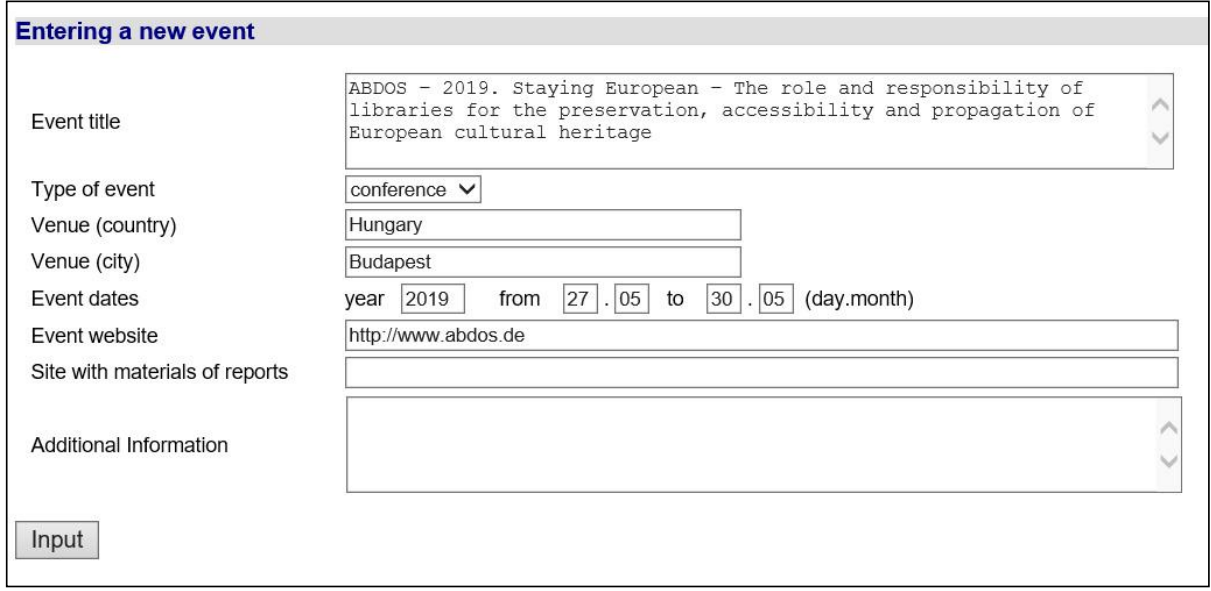

Fig. 2. Registration of the event

It should be noted that the metadata of organizations in the system is presented in the form of a hierarchical structure: an organization can include units that have departments, which, in turn, can include laboratories, etc. The system administrator enters the name of the organization, then the names of its departments, then links the names of departments to organization, etc. In fig. 3 shows the interface for editing organizations on the example of the organization "Scientific Research Institute for System Analysis of the Russian Academy of Sciences (SRISA RAS)". Here you can edit the names of the organization and departments, add (or delete) departments at any level.

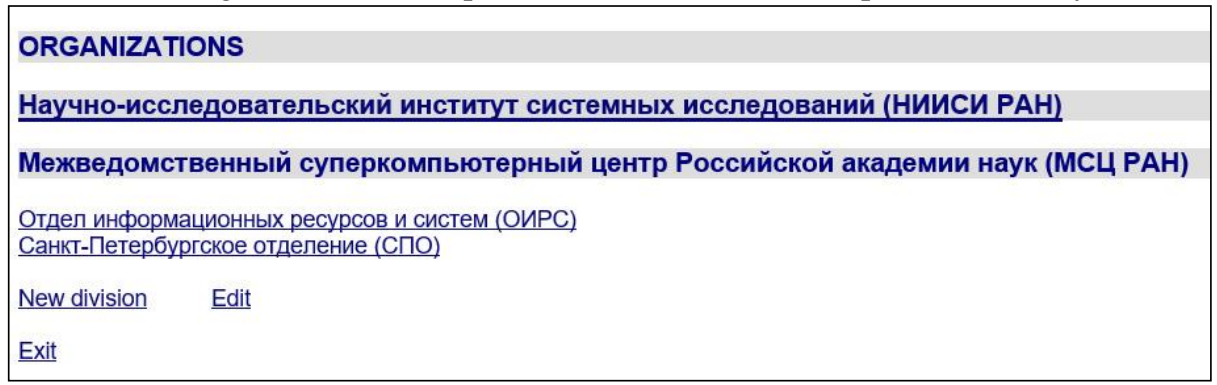

Fig. 3. Administrative block. Editing an organization

\section{System custom module}

The user block of the system provides the ability to form different kinds of queries to the system, displays the information found on the screen and provides navigation through various related objects. When creating the search interface, we used the approaches implemented by the authors in other developments, the effectiveness of which has been confirmed in practice $[10,11]$. To form a query in the search form (Fig. 4) terms are entered in one, two or three lines. Strings are connected by logical operators "AND", "OR", "AND NOT". Several terms can be entered in each line by 
connecting them with logical "AND" or "OR". It is possible to truncate the term on the right using the symbol "*".

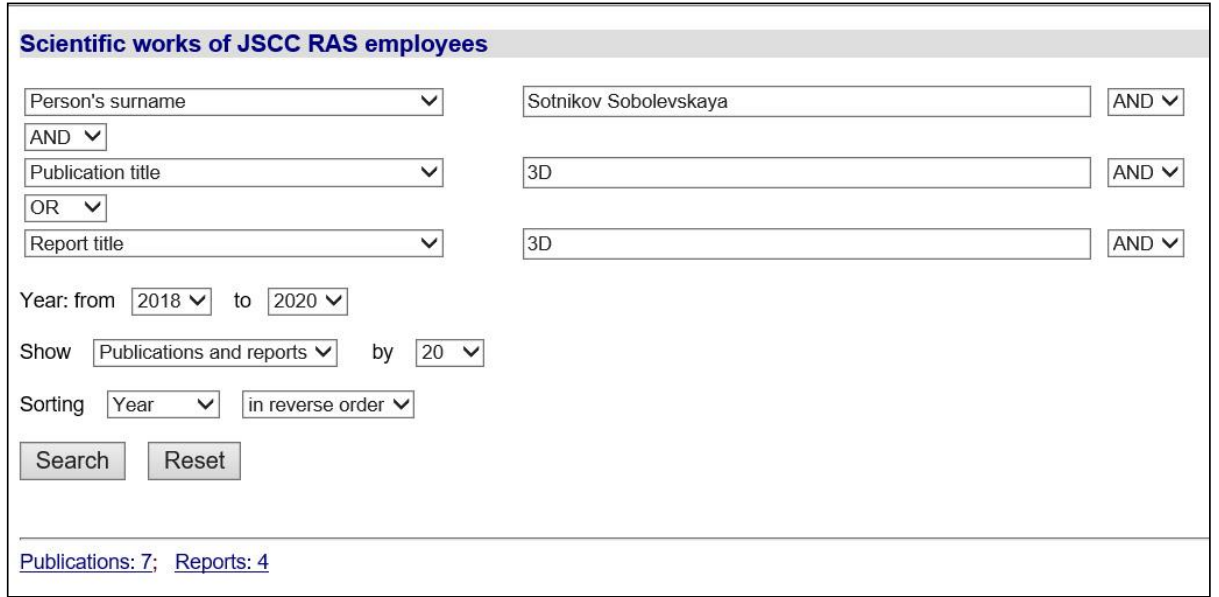

Fig. 4. Search engine form

For each line of entered terms in the search form, the name of the class attribute is selected in which the search should be performed:

$\checkmark$ Person's surname

$\checkmark$ Publication title

$\checkmark \quad$ Title of the journal / collection

$\checkmark \quad$ Title of the report

$\checkmark$ Event (name, country, city)

$\checkmark$ Organization (name, division)

$\checkmark \quad$ Identifier in external databases

By default, in the search form, the first line contains the field "Name of the person", the second - "Title of the publication", the third - "Title of the report". The search query can be limited to the years of publications (events) by selecting the required years from the drop-down lists "Year of publication from ... to ...". Search results can be sorted by year or alphabetically by descriptions of found objects in forward or reverse order. By default, sorting is performed by year in reverse order (publications (events) of the current year are displayed first). In the search form of the system, it is possible to customize the issuance of the found information by selecting the required line from the "Show" drop-down list:

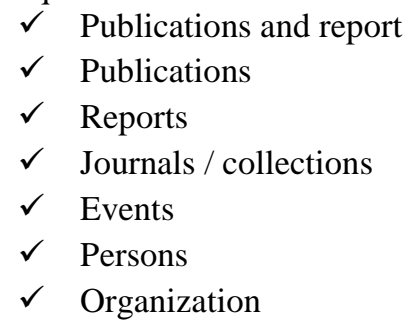


By default, the option "Publications and reports" is selected in the search form. The result of running search queries is displayed on the screen in portions, the size of which is specified in the "Show ... by ..." drop-down list (by default - 20 documents per page). If all search fields are left empty and click on the "Search" button, the system will display all registered objects in accordance with the selected "Show" option.

Consider the results of the processing of search queries by the system with different options for choosing the display of found objects.

\section{Publications and reports}

Fig. 4 demonstrates an example of a search request for joint publications and reports for 2018-2020 is given, the titles of which contain the term "3D", and the coauthors include "Sotnikov" and "Sobolevskaya". By this request, the system finds: "Publications 7", "Reports 4" (Fig. 4). Clicking on the link "Publications ..." opens a list of publications in a new browser window; following the link "Reports ..." - a list of reports (see below).

\section{Publications}

Publications are issued in the form of standard bibliographic descriptions, in which the authors and names of journals (collections) are active links (Fig. 5). In the event that the publication metadata contains a URL to the full text of the publication, the title of the publication will also be an active link, following which will open the article in a new browser window.

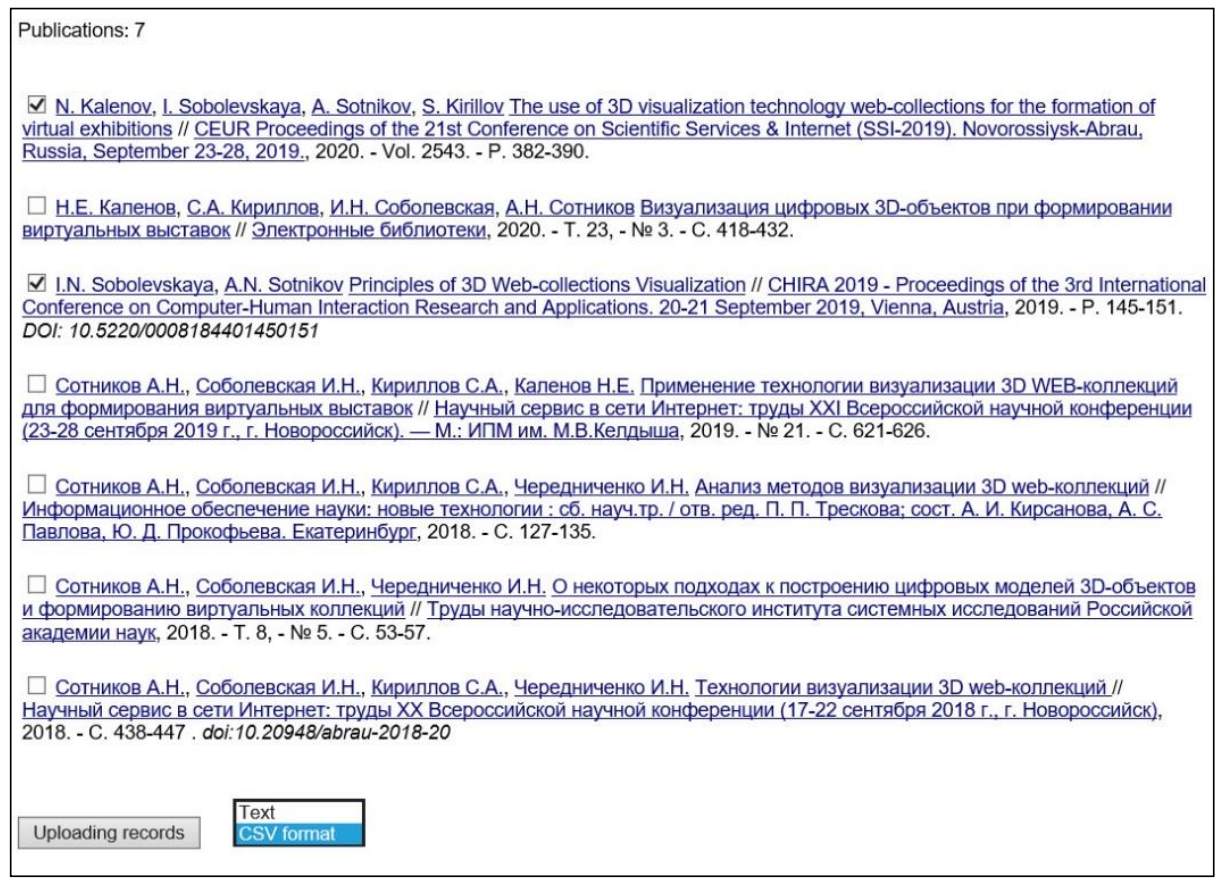

Fig. 5. Bibliographic descriptions of found publications 
Following the link from the author's surname will show in a new browser windowall articles of this author registered in the system are displayed. In addition, the system will show the name of the organization to which the author belongs and additional information related to it. The link from the name of the organization allows you to go to articles of all persons belonging to this organization.

In the bibliographic description of the publication, when clicking on the link from the name of the source (journal, collection), the user will receive in a new browser window descriptions of all articles registered in the system and published in this source.

The system provides the ability to unload the bibliographic descriptions of the publications required by the user represented in two types: standard text form or into a structured file of CSV format. Records of files of the first type can be included in the list of cited bibliography by simple copying, records of the second - in the EXCEL table for subsequent use in the user's personal library.

To unload bibliographic records, the user puts "check marks" next to the publications he needs, selects the required format at the bottom of the viewing page and clicks the "Unload records" button. You can mark records on any page of viewing the found publications; when you go through the pages, the "check marks" are saved. You can also click the Upload Records button on any of the pages. After clicking it, the unloaded file of the selected structure is shown in a new window. The bibliographic descriptions of publications can be copied by the user to their computer with simple copy / past options. If the user selects the CSV format, the button "Download file" appears on the screen, after clicking on which the records are uploaded to a file with the CSV extension on the user's PC, upon opening which a table with the following columns is generated in EXEL:

$\checkmark$ Authors

$\checkmark$ Publication title

$\checkmark$ Source name

$\checkmark \quad$ The year of publishing

$\checkmark$ Tom

$\checkmark$ Number

$\checkmark$ Pages

$\checkmark$ Identifiers in external databases

$\checkmark \quad$ Full text address

$\checkmark$ Additional Information

$\checkmark$ Reports

Descriptions of reports contain: the authors of the report, the title of the report, a description of the event at which the report was made. The names of the authors are active links, the transition to which will ensure the issuance in a new browser window of all the reports of this author registered in the system. The system will show the name of the organization to which the author belongs, as well as additional information. The link on the name of the organization allows you to go to the descriptions of the reports of all persons related to this organization. 


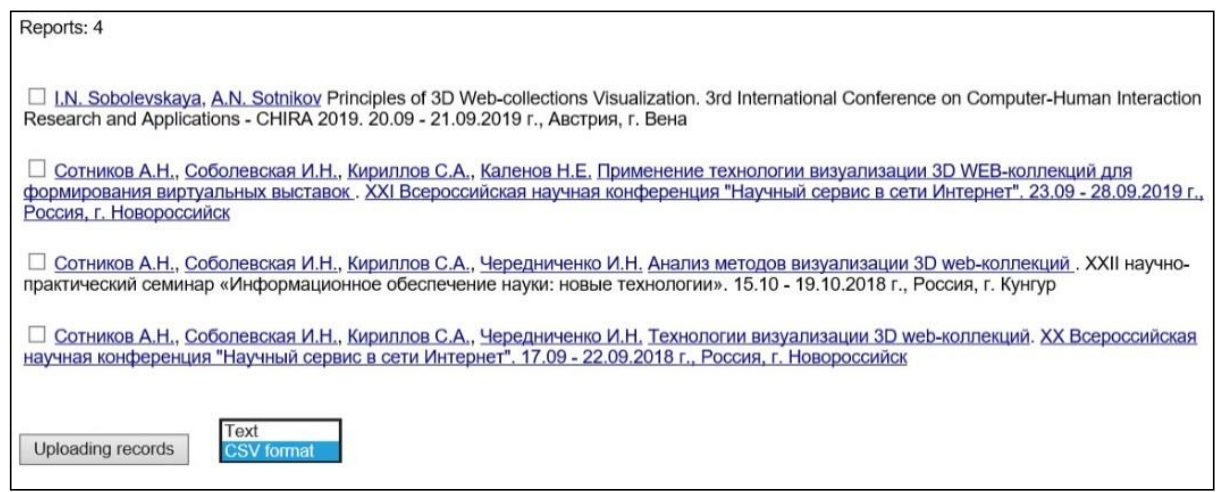

Fig. 6. List of found reports

If the address of the site with additional information about a particular report is known and entered into the system, its name in the list (Fig. 6) will be presented as an active link, by which the user can go to the text or presentation of the report. The link from the name of the event opens event website.

The system allows you to unload selected report records in text format and CSV format. The procedure for selecting and unloading records of reports is completely identical to that described above for unloading publications. When unloading in CSV format, an EXEL table is formed with the following columns:

$\checkmark$ Authors

$\checkmark \quad$ Title of the report

$\checkmark$ Event title

$\checkmark$ Year of the event

$\checkmark$ Event start date

$\checkmark$ End date of the event

$\checkmark$ Country

$\checkmark$ City

$\checkmark$ Event website

$\checkmark$ Site with materials of reports

$\checkmark$ Journals / collections of articles

In accordance with the processed search query, the system gives out the found information about publications at the consolidated level ("sources") - magazines, collections. The names of the sources are active links, clicking on which you will see all publications related to the selected source in a new browser window.

\section{Reports}

The system displays descriptions of the events found, in which the names are active links. By clicking on the name of the event we will receive a list of all reports related to the selected event and registered in the system, in a new browser window.

\section{Persons}

An example of a request to search for persons whose articles have been published in the CEUR Proceedings in 2020 is shown in the Fig. 7. The list displayed on the 
screen includes the names and initials of the found persons and the names of the organizations associated with them.

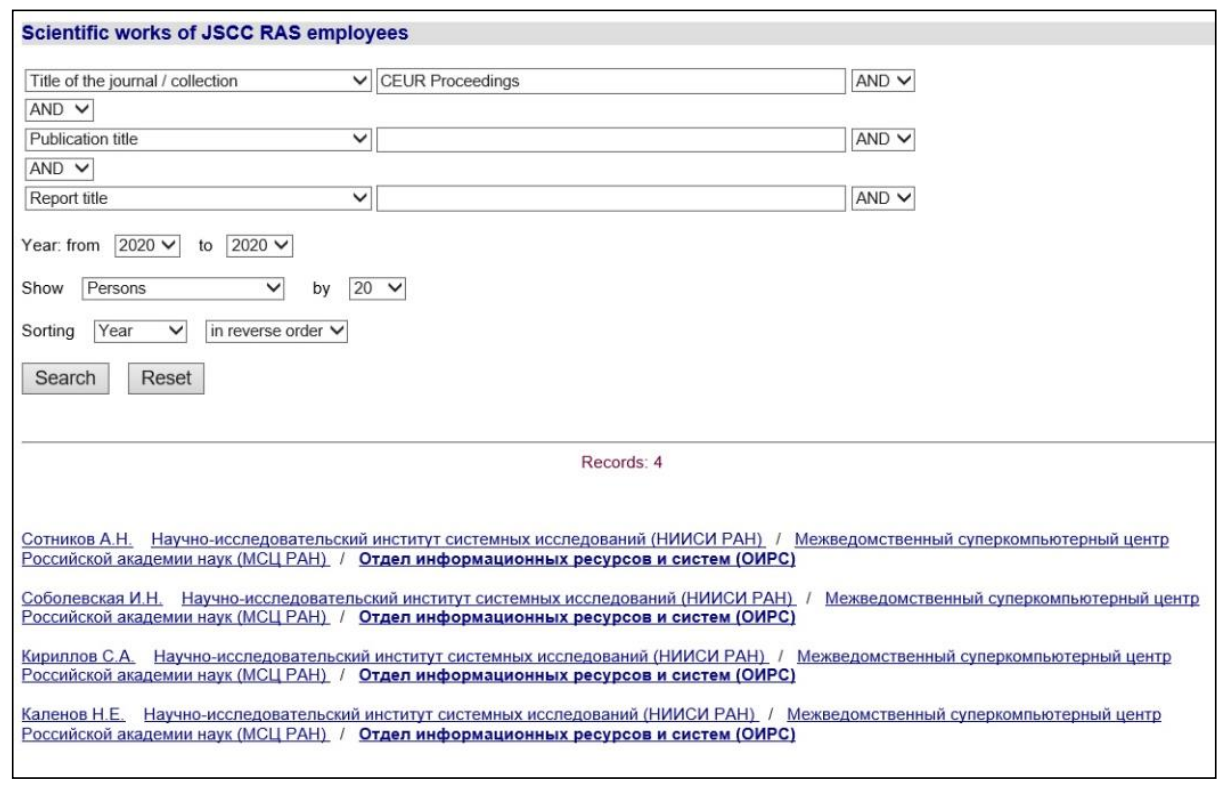

Fig. 7. An example of a request to search for persons

Surnames of persons are active links, upon clicking on which in a new browser window all information about the selected person available in the system will be displayed: organization name (active link), additional information, number of publications ("Publications ..." - active link) and reports ("Reports ..." - active link). Clicking on the links "Publications ..." and "Reports ..." allows you to get descriptions of all publications and reports of a person. Going by the name of the organization opens a new window with information about it (see below).

\section{Organizations}

The metadata of organizations in the system is presented in the form of a hierarchical structure (an organization can include departments, for example, departments, which, in turn, can include laboratories, etc.). When a user selects organizations as search results, the system displays a list of found objects whose names are active links. If, as a result of the search, a subdivision of an organization is found, then the system shows not only it, but also all subdivisions of this organization higher in the hierarchy. For example, for the found subdivision "Department of Information Resources and Systems (OIRS)" (Fig. 7), the system will show the record: "Scientific Research Institute for System Analysis of the Russian Academy of Sciences (SRISA RAS) / Joint Supercomputer Center of the Russian Academy of Sciences (JSCC RAS) / Department of Information Resources and Systems (OIRS) ", in which all names separated by" / "are active links. When you click on the link of the selected name, the system will show all publications and reports, the authors of which are employees of this unit or organization as a whole. 


\section{Conclusion}

As shown above, the search engine of the presented system provides users with convenient navigation through related objects: from the found article to the source in which it is published, and then to all the articles of this source registered in the system; from the found report to the event at which it was made, and then to all the reports of this event; from the author to his publications and reports; from the organization to its employees and to all their scientific works.

At present, the system is successfully operating in the technological mode at JSCC RAS. The operation of the system (inputting and editing of records) is carried out by one administrator. The users of the system are researchers at the JSCC RAS. 325 persons from 46 organizations are registered in the system; 743 articles published in 349 editions. In addition, this year began inputting the reports made at scientific events. There were registered 25 events and 39 reports made in 2018-2020.

The work was carried out at the JSCC RAS - Branch of SRISA RAS, within the framework of state assignment No. 0580-2021-0014.

\section{References}

1. Mazov, N.A., Gureev, V.N.: Bibliograficheskaya baza dannykh trudov sotrudnikov organizatsii: tseli, funktsii, sfera ispol'zovaniya v naukometrii. Vestnik Dal'nevostochnoy gosudarstvennoy nauchnoy biblioteki, 2 (71), 84-87 (2016).

2. Beskaravaynaya, E.V., Dovbnya, E.V., Zakharova, S.S.: Problemno-orientirovannye kollektsii. Formirovanie i analiz na primere bazy dannykh trudov sotrudnikov Instituta biofiziki kletki. Bibliografiya, 4, 30-36 (2008).

3. Levchenko, O.I., Solov'ev, A.V.: Formirovanie bazy dannykh publikatsiy sotrudnikov Instituta fiziki tverdogo tela RAN. In: Informatsionnoe obespechenie nauki: novye tekhnologii: Sbornik nauchnykh trudov, 215-221 (2015).

4. Publikatsii sotrudnikov MIAN, http://www.mi-ras.ru/index.php?c=mianpubs\&l= 0\&jrnfilters[]=jhep, last accessed 2020/11/17.

5. Publikatsii sotrudnikov Instituta Evropy RAN, http://www.ieras-library.ru/a-z.htm, last accessed 2020/11/17.

6. Koroleva, I.Yu., Bakhmad, E.A., Kurochkina, E.V.: Kartoteka publikatsiy dlya EBS VolgGTU. Molodoy uchenyy, 6, 64-67 (2012).

7. Vlasova, S.A., Kalenov, N.E.: Informatika $\mathrm{v}$ akademicheskoy biblioteke. Sistemy i sredstva informatiki, 26 (3), 162-178 (2016).

8. Vlasova, S.A.: Avtomatizirovannaya sistema podderzhki korporativnoy bazy dannykh nauchnykh publikatsiy. Programmnye produkty, sistemy i algoritmy, 2, 42-46 (2018).

9. Vlasova, S.A., Kalenov, N.E.: Novye poiskovye vozmozhnosti i vostrebovannost' kataloga knig i prodolzhayushchikhsya izdaniy BEN RAN. In: Informatsionnoe obespechenie nauki: novye tekhnologii: Sbornik nauchnykh trudov, 171-178 (2016).

10. Vlasova, S.A., Kalenov, N.E.: Internet-katalog Biblioteki po estestvennym naukam Rossiyskoy akademii nauk kak spetsial'naya informatsionno-poiskovaya sistema, orientirovannaya na kvalifitsirovannogo pol'zovatelya. Sistemy i sredstva informatiki, 29(1), 86-95 (2019). 